\title{
'Functional' body composition: differentiating between benign and non-benign obesity
} Manfred J Müller ${ }^{1 *}$, Anja Bosy-Westphal ${ }^{1}$ and Martin Heller ${ }^{2}$

\author{
Addresses: ${ }^{1}$ Institut für Humanernährung und Lebensmittelkunde, Agrar- und Ernährungswissenschaftliche Fakultät, Christian-Albrechts- \\ Universität, Düsternbrooker Weg 17-19, D-24105 Kiel, Germany; ${ }^{2}$ Klinik für Diagnostische Radiologische, Universitätsklinikum Schleswig \\ Holstein, Kiel, Germany \\ * Corresponding author: Manfred J Müller (mmueller@nutrfoodsc.uni-kiel.de) \\ FI000 Biology Reports 2009, I:75 (doi:I0.34I0/BI-75)
}

The electronic version of this article is the complete one and can be found at: http://FI000.com/Reports/Biology/content/I/75

\begin{abstract}
Recent body composition analyses, together with assessments of insulin resistance, aerobic fitness, and intima-media thickness of the common carotid artery, have shown that metabolically-benign obese subjects have a similar BMI, waist circumference, and subcutaneous abdominal fat compared with non-metabolically-benign obese subjects. Research has suggested that $25-30 \%$ of the obese population do not need either treatment or prevention of secondary disorders. Therefore, assessment of functional body composition should replace nutritional status-based risk assessments (such as the body mass index) in both metabolic research and clinical decision making. The concept of 'functional' body composition gives us a more sophisticated view on nutritional status, metabolism, endocrinology, and diseases. Knowledge of detailed body composition enables characterization of biomedical traits which will give functional evidence relating genetic variants.
\end{abstract}

\section{Introduction and context}

The current practices to assess nutritional status include the calculation of body mass index (BMI) by dividing weight $(\mathrm{kg})$ by the square of the height $(\mathrm{m})$. Normative data are most frequently used to identify over- and underweight subjects. In the overweight, waist circumference is measured for additional assessment of health risks. Recent methodological and technological advances [for example, using magnetic resonance imaging (MRI) and dual energy X-ray absorptiometry (DXA) technologies] have enabled accurate and detailed body composition analysis (BCA) and assisted in the development of advances in body composition, endocrine, and metabolic research. BCA is now standard in investigations on energy and macronutrient metabolism. The introduction of valid field methods such as bioelectrical impedance analysis (BIA) has led to broader applications of BCA within epidemiological and clinical studies. The present commentary aims to discuss the utility of body composition data in the assessment of metabolic, endocrine, and physical function. This article will have a major focus on the regulation of energy expenditure and energy balance.

Assessment of body components and modeling of body composition at molecular, cellular, and tissue levels results in the identification of different characteristics of the body [for example, tissue hydration, electrical resistance, mineral content, kilograms of fat, and fat-free mass (FFM)] [1]. Within epidemiology, these data can be used to generate population-specific reference values and suitable cut-offs (for example, by using percentiles to characterize over- and underweight subjects) $[2,3]$. BCA data (such as body fat distribution) may also be included in scores used for assessment of cardiometabolic risk $[4,5]$. Characterising individual body components also helps to identify specific types of malnutrition via the assessment of body fat and muscle mass (for example, identification of sarcopenia with reduced skeletal muscle mass at normal or increased fat mass in patients with rheumatoid arthritis [6]). BCA data are also associated with clinical prognosis, for 
example, a low phase angle as assessed by BIA was shown to predict survival in severely ill patients [7]. Assessment of body components and how they change with regard to nutrition, development, inflammation, and/or wasting disease is mandatory for understanding metabolism, for example, how it changes in response to starvation [8], health (for example, muscle mass is one determinant of bone health [9]), and clinical outcome (in the case of wasting diseases [7]).

\section{Major recent advances Impact of fat mass on energy balance}

FFM is the major determinant of energy expenditure and can account for about $60-80 \%$ of the variance in energy expenditure [10]. Recent work also shows that the higher the amount of FFM, the higher the resting energy expenditure (REE). FFM is heterogeneous and the proportion of muscle and organ mass contributes to the variance in REE [11]. On the other side of the energy balance equation, there is a close and exponential association between fat mass (FM) and plasma leptin concentrations, which are considered to be a major signal in regulating appetite and thus energy intake [12]. Higher FM tends to correlate with higher plasma leptin levels. Reducing FM increases energy intake by lowering leptin secretion rates, whereas decreasing FFM lowers REE. The reverse of the previous sentence is also true; increases in FM are associated with high plasma leptin levels and increases in FFM with high REE.

\section{Evidence that fat mass affects energy metabolism}

Overweight and obese subjects have a higher REE than their lean controls, mainly explained by their higher FFM. However, REE differences between lean and obese subjects remained after adjustments for FFM and age [13]. In addition, most of the between-group differences in REE disappeared after further adjustment for FM. Based on multiple regression analyses, energy expenditure of FFM was found to be three to seven times greater than energy expenditure of FM [14]. A recent study used regression analyses to show that the relative contribution of FM on the variance in REE increased from low to normal with increasing grades of adiposity (that is, up to a FM of $40 \%$ body weight) but sharply decreased at very high ( $>40 \%$ FM) and extreme ( $>50 \% \mathrm{FM}$ ) grades of obesity [15]. The latter finding might suggest a threshold effect of FM that cannot be explained on the basis of present knowledge, however, it may suggest that the metabolic rate of FM is reduced in very obese subjects, that is, FM itself has a 'thermic effect' on metabolic rate that varies with its mass.

\section{Explaining how fat mass regulates REE}

Fat cells normally have a low metabolic rate $(19 \mathrm{~kJ}$ or about $5 \mathrm{kcal} / \mathrm{kg} \times \mathrm{d}[14,16])$, but another recent study suggests that the mass-dependent effect of FM may be explained, not by fat cell metabolism itself, but by the secretory activity of fat cells (for example, secretion of adipocytokines and/or hormones). It can also be explained by metabolic, inflammatory, and haemodynamic disturbances associated with being overweight [16]. A high FM and abdominal obesity are frequently associated with metabolic disturbances (such as insulin resistance and increased sympathetic nervous system activity) and co-morbidity (for example, different traits of the metabolic syndrome), which add to the variance in REE. Also, insulin resistance and elevated blood pressure are associated with higher REE, even after adjustments for FFM, FM, and age [17].

Data on patients with partial lipodystrophy syndromes (characterized by a loss of subcutaneous fat, low plasma levels of adipocytokines, and a greater percentage of trunk fat, as well as the presence of ectopic fat in nonadipose tissue such as skeletal muscle and the liver) provide further information on the role of FM in regulating REE. In patients with congenital lipodystrophies, REE is $20-70 \%$ higher than normal levels [18]. REE per $\mathrm{kg}$ of FFM was also higher in patients with HIV lipodystrophy compared with HIV-infected patients without lipodystrophy [19]. A recent study proposes that this increase in REE is a compensatory mechanism to dissipate calories which cannot be stored normally [19]. These data suggest that REE can be affected in different and indirect ways depending on the location of the fat depots (that is, subcutaneous, visceral, or ectopic fat), and the storage capacity of the adipocytes.

A recent study showed that, in adults, the number of fat cells stays constant and about $10 \%$ of fat cells are renewed annually [20]. The mean size of adipocytes increases with FM up to a point and then decreases. Adipocyte cellularity and triglyceride accumulation within lipid droplets is associated with morbidity. However, the association between adipocyte size and FM differs with region. Enlarged abdominal adipocytes are associated with visceral and subcutaneous abdominal fat, whereas femoral adipocyte size is related to percentage body fat, and gluteal adipocyte size is related to visceral fat [21]. Enlarged subcutaneous fat cells are associated with insulin resistance, independent of FM [22]. Therefore, large fat cells may also result in a relatively higher REE. There is now evidence from experimental data that lipid droplet structure (large unilocular versus smaller multilocular droplets) is associated with mitochondrial oxidative metabolism, 
and that smaller droplets increase the rate of lipolysis and energy expenditure [23]. Thus, the effect of FM on REE varies with fat depots, fat cell size, and lipid droplet structure.

\section{Is there a feedback between fat mass and energy metabolism?}

The feedback mechanism of FM on energy metabolism is not known, but leptin has been considered as a candidate for such a signal from fat [24]. Animal data have suggested a 'thermic' effect of leptin, and leptin has been shown to directly stimulate thermogenesis in mouse skeletal muscle [25]. It has been proposed that leptin may uncouple proteins [26] and increase substrate cycling between de novo lipogenesis and mitochondrial lipid oxidation [25], and recent work suggests that this is diminishing phosphatidylinositol-3 kinase and AMPactivated protein kinase signaling [27]. When compared with animal data, a 'thermic' effect of leptin is equivocal in humans. Recent observational studies do not suggest that leptin has a 'thermic' effect in normal weight or obese subjects [28]. Using leptin to treat a child that had congenital leptin deficiency [29] and obese patients that had increased plasma leptin concentrations [30] resulted in substantial weight loss but did not affect REE, and REE adjusted for FFM was reduced rather than increased. In obese subjects, leptin administration does not seem to accelerate weight loss as a supplement to diet intervention unless it is given in supraphysiological doses [31]. A recent study showed that, in addition, substituting leptin for the physiological decrease in plasma leptin concentrations in weight-reduced (having undergone a $10 \%$ reduction in body-weight), normal-weight, or overweight healthy subjects had no effect on REE or REE adjusted for FFM [32]. These data argue against a 'thermic' effect of leptin in humans. However, contrary to dose-response characteristics of many hormones, leptin may not have effects at high plasma concentrations; its 'thermic' effect may become obvious below a certain threshold level only. In fact, new data in patients with anorexia nervosa suggest a steep association between plasma leptin levels and REE in underweight patients, which disappears after weight gain (V Haas, K Gaskin, MJ Müller, unpublished data). It is unclear whether the threshold may be changed (for example, in obese subjects with chronically elevated leptin levels).

Metabolic adaptations during weight changes and disease A broader concept of functional body composition includes both mass-dependent and mass-independent alterations in body function. The latter reflects metabolic 'elasticity' and includes mass-independent changes in metabolism in response to different stimuli such as fasting, feeding, work load, short sleep, disease, or stress.
Inter-individual variance in metabolic 'elasticity' contributes to energy balance. Detailed body composition analyses may provide a clue to explain metabolic 'elasticities'. A recent study comparing obese subjects who had large decreases in REE in reponse to caloric restriction with those who had only small diet-induced adaptations revealed that the former patients were 'thrifty' (that is, weight loss in response to hypocaloric nutrition was $8 \mathrm{~kg}$ compared with $10 \mathrm{~kg}$ in the nonthrifty group) and they could conserve fat-free, liver, and kidney mass at a concomitant greater fall in plasma triiodothyronine $\left(\mathrm{T}_{3}\right)$ concentration [33]. The 'thrifty' phenotype could not be identified by any a priori measure of body composition, fat distribution (including liver fat), metabolism, or plasma hormone concentrations. These data suggest that adaptive thermogenesis is related to conservation of FFM and its composition, as well as to $T_{3}$ production. Thus, for a clinician, data on body composition and metabolism should be seen in the broader context of plasma thyroid hormone concentrations and/or biomarkers of stress in order to characterize the metabolic phenotype.

\section{Future directions \\ Genetic basis of energy metabolism}

Body composition and metabolism have underlying genetic components. In family studies, heritability estimates of individual body components are variable, for example, 0.05 for BMI compared with 0.25 for percent body fat (and may exceed 0.50 when individual variables are taken into account) [34,35]. After adjusting REE for FFM, FM, age, and sex, a considerable variance of about $150 \mathrm{kcal} / \mathrm{d}$ remained [36,37] that has not yet been explained. Adjusted REE was moderately heritable (around 0.30 [16,35-37]) but presently there is no clear evidence that specific genes add to the interindividual variance in REE $[38,39]$. In future, research into traits defined by measures of functional body composition (for example, changes in REE-FFM with under- and overfeeding) will provide functional evidence relating genetic variants.

\section{Use of cut-offs in body composition research}

The definitions of both 'overweight' and 'malnutrition' should be reconsidered now that we are faced with the concept of functional body composition. Suitable cutoffs of body weight and/or body components (such as those based on percentiles or health outcomes) do not take into account functional aspects. In future, it is likely that the terms 'overweight' and 'malnutrition' will be defined more in terms of function in the context of body composition (for example, by their affect on metabolism and inflammation) rather than mere nutritional status. Current guidelines recommend weight-loss therapy for patients with a BMI $\geq 30 \mathrm{~kg} / \mathrm{m}^{2}$ and for patients with a 
BMI $\geq 25 \mathrm{~kg} / \mathrm{m}^{2}$ who additionally have a high-risk waist circumference amongst other risk factors. However, there is substantial heterogeneity within obese subjects as to their overweight-associated health risks $[40,41]$, suggesting the need for detailed assessment of body composition together with energy, glucose, and lipid metabolism (that is, an assessment of 'functional' body composition).

\section{Are there healthy obese subjects and can they be identified by assessment of detailed body composition?}

Based on cross-sectional data on 5,440 adult participants of the NHANES (National Health and Nutrition Examination Survey) 1999-2004, 51.3\% of overweight and $31.7 \%$ of obese adults were metabolically healthy as defined via the absence of cardiometabolic abnormalities including elevated blood pressure, hyperlipidemia, insulin resistance, and elevated serum levels of C-reactive protein [40]. Correlates of no- or low-risk in overweight and obese subjects were young age, ethnicity, high leisure time, physical activity, and a small waist circumference. In another clinical study, $25.4 \%$ of obese subjects were characterized as metabolically benign [41]. Body composition analyses (including measurements of ectopic fat in the liver and muscle by MR-spectroscopy) together with assessments of insulin resistance, aerobic fitness, and intima-media thickness of the common carotid artery, showed that metabolically-benign compared with non-metabolically-benign obese subjects had a similar BMI, waist circumference, and subcutaneous abdominal fat, but had slightly lower visceral fat mass and higher ectopic fat deposits in muscle and particularly in the liver [40]. These data suggest that $25-30 \%$ of the obese population do not need either treatment or prevention of secondary disorders. Clearly, detailed body composition measurements have to be combined with a measure of ectopic fat and/or insulin resistance in order to explain the meaning of nutritional status.

To summarize, assessment of functional body composition should replace nutritional status-based risk assessments and needs to be included in metabolic research and clinical decision making.

\section{Abbreviations}

BCA, body composition analysis; BIA, bioelectrical impedance analysis; BMI, body mass index; DXA, dual energy X-ray absorptiometry; FFM, fat-free mass; FM, fat mass; MRI, magnetic resonance imaging; NHANES, National Health and Nutrition Examination Survey; REE, resting energy expenditure; $T_{3}$, triiodothyronine.

\section{Competing interests}

The authors declare that they have no competing interests.

\section{Acknowledgments}

The authors own work was funded by grants from the Deutsche Forschungsgemeinschaft (German Research Foundation); DFG Mü 714/8-3, and the Bundesministerium für Bildung und Forschung (Federal Ministry for Education and Research); BMBF 'Krankheitsprävention durch Ernährung: Nahrungsfette und Stoffwechsel, Genvariabilität, -regulation, -funktion und funktionelle Lebensmittelinhaltsstoffe'.

\section{References}

I. Shen W, St-Onge M-P, Wang Z, Heymsfield SB: Study of Body Composition: An Overview. In Human Body Composition. $2^{\text {nd }}$ edition. Edited by Heymsfield SB, Lohman TG, Wang Z, Going SB. Champaign, IL: Human Kinetics; 2005:3-I4.

2. Pichard C, Kyle UG, Bracco D, Slosman DO, Morabia A, Schutz Y: Reference values of fat free and fat masses by bioelectrical impedance analysis in $\mathbf{3 3 9 3}$ healthy subjects. Nutrition 2000, 1 6:245-54.

3. Bosy-Westphal A, Danielzik S, Dörhöfer RP, Piccoli A, Müller MJ: Patterns of bioelectrical impedance vector distribution by body mass index and age: implications for body-composition analysis. Am J Clin Nutr 2005, 82:60-8.

4. Klein S, Allison DB, Heymsfield SB, Kelley DE, Leibel RL, Nonas C, Kahn R; Association for Weight Management and Obesity Prevention; NAASO, The Obesity Society; American Society for Nutrition; American Diabetes Association: Waist circumference and cardiometabolic risk: a consensus statement from Shaping America's Health: Association for Weight Management and Obesity Prevention; NAASO, The Obesity Society; the American Society for Nutrition; and the American Diabetes Association. Am J Clin Nutr 2007, 85: I | 97-202.

5. Assmann G, Schulte H, Seedorf U: Cardiovascular risk assessment in the metabolic syndrome: results from the Prospective Cardiovascular Munster (PROCAM) Study. Int J Obes (Lond) 2008, 32(Suppl 2):SI I-6.

6. Baumgartner RN: Age. In Human Body Composition. $2^{\text {nd }}$ edition. Edited by Heymsfield SB, Lohman TG, Wang Z, Going SB. Champaign, IL: Human Kinetics; 2005:259-70.

7. Bosy-Westphal A, Danielzik S, Dörhöfer RP, Later W, Wiese S, Müller MJ: Phase angle from bioelectrical impedance analysis: population reference values by age, sex, and body mass index. JPEN J Parenter Enteral Nutr 2006, 30:309-16.

8. Hall KD: Computational model of in vivo human energy metabolism during semistarvation and refeeding. Am J Physiol Endocrinol Metab 2006, 291:E23-37.

9. Goulding A, Grant AM, Williams SM: Bone and body composition of children and adolescents with repeated forearm fractures. J Bone Miner Res 2005, 20:2090-6.

10. Ravussin E, Bogardus C: Relationship of genetics, age, and physical fitness to daily energy expenditure and fuel utilization. Am J Clin Nutr 1989, 49(Suppl 5):968-75.

II. Later W, Bosy-Westphal A, Hitze B, Kossel E, Glüer CC, Heller M, Müller MJ: No evidence of mass dependency of specific organ metabolic rate in healthy humans. Am J Clin Nutr 2008, 88: 1004-9.

12. Ostlund RE Jr, Yang JW, Klein S, Gingerich R: Relation between plasma leptin concentration and body fat, gender, diet, age, and metabolic covariates. J Clin Endocrinol Metab 1996, 8I: 3909-13.

13. Müller MJ, Bosy-Westphal A, Klaus S, Kreymann G, Lührmann P, Neuhäuser-Berthold M, Noack R, Pirke KM, Platte P, Selberg O, Steiniger J: World Health Organization equations have shortcomings for predicting resting energy expenditure in persons 
from a modern, affluent population: generation of a new reference standard from a retrospective analysis of a German database of resting energy expenditure. Am J Clin Nutr 2004, 80: 1379-90.

14. Elia M: Organ and tissue contribution to metabolic rate. In Energy Metabolism: Tissue Determinants and Cellular Corrolaries. Edited by Kinney JM, Tucker HN. New York: Raven Press; 1992:61-77.

15. Bosy-Westphal A, Müller MJ, Boschmann M, Klaus S, Kreymann G, Lührmann PM, Neuhäuser-Berthold M, Noack R, Pirke KM, Platte $P$, Selberg O, Steininger J: Grade of adiposity affects the impact of fat mass on resting energy expenditure in women. $\mathrm{Br}$ J Nutr 2009, 101:474-7.

16. Ahima RS: Adipose tissue as an endocrine organ. Obesity 2006, I4:S242-9.

17. Bosy-Westphal A, Wolf A, Bührens F, Hitze B, Czech N, Mönig H, Selberg $O$, Settler U, Pfeuffer M, Schrezenmeir J, Krawczak M, Müller MJ: Familial influences and obesity-associated metabolic risk factors contribute to the variation in resting energy expenditure: the Kiel Obesity Prevention Study. Am j Clin Nutr 2008, 87:|695-70|.

18. Cutler DL, Kaufman S, Freidenberg GE: Insulin-resistant diabetes mellitus and hypermetabolism in mandibuloacral dysplasiea: a newly recognized form of partial lipodystrophy. J Clin Endocrinol Metab 199|, 73:|056-6I.

19. Kosmiski L, Bessesen DH, Stotz SA, Koeppe JR, Horton TJ: Shortterm overfeeding increases resting energy expenditure in patients with HIV-lipodystrophy. Am J Clin Nutr 86:1009-I5.

20. Spalding KL, Arner E, Westermark PO, Bernard S, Buchholz BA, Bergmann $O$, Blomqvist L, Hoffstedt J, Näslund E, Britton T, Concha H, Hassan M, Rydén M, Frisén J, Arner P: Dynamics of fat cell turnover in humans. Nature 2008, 453:783-7.

FI000 Factor 7.I Must Read

Evaluated by Michael Symonds 29 May 2008, Michele Forman 02 Jun 2008, Anthony Means 10 Jun 2008, William H Colledge 13 Jun 2008, Jonathan Slack 17 Jun 2008, Ray Rodgers 14 Jul 2008

21. Tchoukalova YD, Koutsari C, Karpyak MV, Votruba SB, Wendland E, Jensen MD: Subcutaneous adipocyte size and body fat distribution. Am J Clin Nutr 2008, 87:56-63.

22. Weyer C, Foley JE, Bogardus C, Tataranni PA, Pratley RE: Enlarged subcutaneous abdominal adipocyte size, but not obesity itself, predicts type II diabetes independent of insulin resistance. Diabetologia 2000, 43:1498-506.

23. Puri V, Czech MP: Lipid droplets: FSP27 knockout enhances their sizzle. J Clin Invest 2008, I 18:2693-6.

24. Leibel RL: The role of leptin in the control of body weight. Nutr Rev 2002, 60 (I0 Pt 2):SI5-9.

25. Solinas G, Summermatter S, Mainieri D, Gubler M, Pirola L, Wymann MP, Rusconi S, Montani JP, Seydoux J, Dulloo AG: The direct effect of leptin on skeletal muscle thermogenesis is mediated by substrate cycling between de novo lipogenesis and lipid oxidation. FEBS Lett 2004, 577:539-44.

26. Porter RK, Andrews JF: Effects of leptin on mitochondrial 'proton leak' and uncoupling proteins: implications for mammalian energy metabolism. Proc Nutr Soc 1998, 57:455-60.

27. Summermatter S, Mainieri D, Russell AP, Seydoux J, Montani JP, Buchala A, Solinas G, Dulloo AG: Thrifty metabolism that favors fat storage after caloric restriction: a role for skeletal muscle phosphatiylinositol-3-kinase activity and AMP-activated protein kinase. FASEB J 2008, 22:774-85.
28. Blaak E, Hul G, Verdich C, Stich V, Martinez JA, Petersen M, Feskens EF, Patel K, Oppert JM, Barbe P, Toubro S, Polak J, Anderson I, Astrup A, MacDonald I, Langin D, Sørensen T, Saris WH; NUGENOB Consortium: Impaired fat-induced thermogenesis in obese subjects: The NUGENOB study. Obesity (Silver Spring) 2007, 1 5:653-63.

29. Farooqi IS, Jebb SA, Langmack $G$, Lawrence $E$, Cheetman $\mathrm{CH}$, Prentice AM, Hughes IA, McCamish MA, O'Rahilly S: Effects of recombinant leptin therapy in a child with congenital leptin deficiency. N Engl J Med 1999, 341:879-84.

30. Westerterp-Platenga MS, Saris WH, Hukshorn CJ, Campfield LA: Effects of weekly administration of pegylated recombinant human OB protein on appetite profile and energy metabolism in obese men. Am J Clin Nutr 200I, 74:426-34.

3I. Heymsfield SB, Greenberg AS, Fujioka K, Dixon RM, Kushner R, Hunt T, Lubina JA, Patane J, Self B, Hunt P, McCamish M: Recombinant leptin for weight loss in obese and lean adults: a randomized, controlled, dose-escalation trial. JAMA 1999, 282:1568-75

32. Rosenbaum M, Goldsmith R, Bloomfield D, Magnano A, Weimer L, Heymsfield S, Gallagher D, Mayer L, Murphy E, Leibel RL: Low-dose leptin reverses skeletal muscle, autonomic, and neuroendocrine adaptations to maintenance of reduced weight. J Clin Invest 2005, I I 5:3579-86.

33. Bosy-Westphal A, Kossel E, Goele K, Later W, Hitze B, Settler U, Heller M, Glüer CG, Heymsfield SB, Müller MJ: Contribution of individual organ mass loss to weight loss-associated decline in resting energy expenditure. Am J Clin Nutr 2009, 90:993-100I.

34. Bouchard C, Pérusse L: Genetics of Obesity: Family Studies. In The Genetics of Obesity. Edited by Bouchard C. Boca Raton, Florida: CRC Press; 1994:79-92.

35. Bosy-Westphal A, Onur S, Geisler C, Wolf A, Korth O, Pfeuffer M, Schrezenmeir J, Krawczak M, Müller MJ: Common familial influences on clustering of metabolic syndrome traits with central obesity and insulin resistance: the Kiel obesity prevention study. Int J Obes (Lond) 31:784-90.

36. Chung WK, Leibel R: Considerations regarding the genetics of obesity. Obesity (Silver Spring) 2008, 16:S33-9.

37. Bouchard C, Dériaz O, Pérusse L, Tremblay A: Genetics of energy expenditure in humans. In The Genetics of Obesity. Edited by Bouchard C. Boca Raton, Florida: CRC Press; 1994:135-46.

38. Bogardus C, Lillioja S, Ravussin E, Abbott W, Zawadzki JK, Young A, Knowler WC, Jacobowitz R, Moll PP: Familial dependence of the resting metabolic rate. $N$ Engl J Med 1986, 315:96-I00.

39. Krakoff J, Ma L, Kobes S, Knowler WC, Hanson RL, Bogardus C, Baier LJ: Lower metabolic rate in individuals heterozygous for either a frameshift or a functional missense MC4R variant. Diabetes 2008, 57:3267-72.

40. Wildman RP, Muntner P, Reynolds K, McGinn AP, Rajpathak S, Wylie-Rosett J, Sowers MF: The obese without cardiometabolic risk factor clustering and the normal weight with cardiometabolic risk factor clustering: prevalence and correlates of 2 phenotypes among the US population (NHANES 1999-2004). Arch Intern Med 2008, 168:1617-24.

4I. Stefan N, Kantartzis K, Machann J, Schick F, Thamer C, Rittig K, Balletshofer B, Machicao F, Fritsche A, Häring HU: Identification and characterization of metabolically benign obesity in humans. Arch Intern Med 2008, 168:1609-16.

FI000 Factor 3.0 Recommended

Evaluated by Caryl Nowson 20 Nov 2008 